\title{
The use of levonorgestrel-releasing intrauterine devices in adolescents - own experience
}

\author{
Agnieszka Drosdzol-Cop@, Iwona J. Czech®, Rafal Stojko®, Violetta Skrzypulec-Plinta® \\ Department of Woman's Health, School of Health Sciences in Katowice, Medical University of Silesia, Katowice, Poland
}

\begin{abstract}
It is estimated that $19 \%$ of adolescents in Poland begin their sexual life when they are 15 years old and more than $50 \%$ of people aged 17-19 years have already had their first sexual contact. World Health Organization recommends teenagers to use the method of 'dual protection' (condom and other method of contraception, i.e. intrauterine devices).

In this study, we sought to present our own experience in the field of the use of levonorgestrel-releasing intrauterine devices in adolescents and to compare it with the experience of other researchers worldwide.

Low- dose levonorgestrel-releasing intrauterine device is safe and effective method of contraception in adolescents. It is also an alternative treatment used in heavy chronic abnormal uterine bleeding. It can be also used as an alternative in women with cyanotic heart disease who have contraindications for standard contraception.

Gynecologists and pediatricians should be well informed in the topic of intrauterine device use among adolescents and they should provide them reliable knowledge in this field.
\end{abstract}

Key words: levonorgestrel-releasing intrauterine device; IUD; AUB; heavy menstrual bleeding

Ginekologia Polska 2020; 91, 6: 342-345

\section{INTRODUCTION \\ Adolescent sexual behavior}

It is estimated that $19 \%$ of adolescents in Poland begin their sexual life when they are 15 years old and more than $50 \%$ of people aged $17-19$ years have already had their first sexual contact [1]. World Health Organization (WHO) estimates that 16 million adolescent girls get pregnant each year [2]. Although the access to medical information is getting easier, health-care worldwide is better than in the past and there is general technological progress, the number of teenage pregnancies is still growing. Unwanted pregnancy is connected with many consequences such as medical consequences of early pregnancy, sexually transmitted infections (STIs), unsafe abortions, social and personal consequences. Because of that, adolescent pregnancy prevention is one of the most important health-care issues of the twenty-first century.

European Society of Contraception and Reproductive Health Care emphasized that only $55 \%$ of young Europeans have access to education in the field of sexuality. Studies show that teenagers often don't know about the methods of contraception and risk sexual behaviors [3].
World Health Organization recommends teenagers to use the method of 'dual protection' (condom and other method of contraception) in order to simultaneously protect against pregnancy and STIs. Intrauterine devices (IUD) represent long-acting reversible contraception (LARC) and they are safe, effective and well-tolerated method of contraception for adolescents.

The Polish Society of Gynecologists and Obstetricians remains consistent with the recommendations of WHO. They emphasize that the method of contraception should be safe, effective, reversible, easy in use and easily accessible [4].

In this study, we sought to present our own experience in the field of the use of levonorgestrel-releasing intrauterine devices (LNG-IUDs) in adolescents and to compare it with the experience of other researchers worldwide.

\section{CURRENT STATE OF KNOWLEDGE AND OWN EXPERIENCE}

Levonorgestrel-releasing intrauterine devices in adolescents

Over 150 million women worldwide use the IUDs for contraception [5]. As a result of various contraceptive ac- 
tions, the efficacy rate of the LNG-IUD is high, which makes it a great option for young women.

Four hormonal levonorgestrel-releasing IUDs (LNG-IUDs) are currently available in Poland (containing different doses of LNG: 13.5 mg, $19.5 \mathrm{mg}, 52 \mathrm{mg}$ ). IUDs should not be used in patients before the first menstruation. We should emphasize that only some devices are dedicated for teenagers [data about being used in women under 18 years old is contained in the Summary of Product Characteristics (SmPC)]. What is more, the devices have different dimensions. We recommend using low-dose IUDs that are fitted to a smaller uterus.

\section{Six - step procedure to introduce IUD}

Physicians from INTRA (Intrauterine Contraception Translating Research Into Action) have proposed 7-minutes algorithm of introducing intrauterine device, which we highly recommend in everyday practice [6]:

Step 1

- Adjust patient's expectations to her needs. Evaluate experience and knowledge about various contraceptive methods.

- Ask simple questions: What contraceptive did you use? Are you currently sexually active? Are you planning a pregnancy?

Step 2

- Present long-acting reversible contraception (LARC).

- Regardless of the reason for the visit, ask the patient about her contraception.

- Assess the patient's knowledge and interest in intrauterine contraception.

Step 3

- Inform about the potential benefits of intrauterine contraception.

- When the patient is interested, expand your information to include: high efficacy, no need for daily, weekly or monthly administration, rapid reversibility, cost- effectiveness, and quick insertion in most women.

Step 4

- Confirm method reliability and dispel doubts.

- Inform about potential side effects such as the risk of ectopic pregnancy, perforation, expulsion or prolapse, infection, and changes in menstrual bleeding patterns.

- Refer to side effects for other methods of contraception and pregnancy itself.

Step 5

- Help to make a decision.

- Share your knowledge and clinical experience. Ask if the patient is interested in seeing the system. Be honest when you talk about discomfort issues.

Step 6

- Confirm the decision and plan the insertion of the IUD.
- Inform that if serious side effects occur, they should contact their physician immediately.

In addition, The Polish Society of Gynecologists and Obstetricians recommends performing before introducing a new method of contraception:

- Physical examination including blood pressure measure;

- Gynaecological examinations;

- Transvaginal ultrasound examinations;

- Breast examinations;

- Cytology test.

According to WHO recommendations, hormonal contraception can be introduced in teenagers [2]:

- 2 years after menarche;

- In the case of dysmenorrhea.

LNG-IUDs are also a great alternative for women with cyanotic heart disease with contraindication to standard hormonal therapy use.

\section{LNG-IUD as a method of treatment of abnormal uterine bleeding}

Abnormal uterine bleeding (AUB) is one of the most frequent condition with which teenagers present in gynecologic office. The most common causes of AUB in adolescents are anovulation and coagulopathy. The initial management of AUB in adolescents is based on whether the AUB is acute or chronic. The second type occurs when uterine bleeding is abnormal in volume, regularity, and/or timing and has occurred for most of the past 6 months. It does not require urgent treatment (unlike acute AUB). LNG-IUD is an excellent management option for a patient experiencing chronic abnormal uterine bleeding. It is more effective than oral medication as a treatment for heavy menstrual bleeding and it is associated with a greater reduction in heavy menstrual bleeding and improvement in quality of life, and appears to be more acceptable long term [7].

In our practice, we have been using several LNG-IUD as an alternative method of treatment in heavy chronic AUB in adolescents (off-label treatment) without observing side effects. Our experience in this field involves 3 girls aged 14-16 with contraindications to use estrogens (implementation of heart valve in childhood, congenital cyanotic heart disease). All three patients have not begun their sexual life yet. Formal consent from their parents for implementation of LNG-IUD was required in all 3 cases.

We would like to present closer a case of 14-year-old girl with cyanotic heart disease who presented with abundant menstruations and irregular cycles. The girl underwent several cardiac surgeries and she is still prepared for subsequent interventions. She uses permanent anticoagulants - under INR control and she has absolute contraindications for estrogen use. On physical examination: peripheral cyanosis, „rod-like fingers". Gynecological 
condition was suitable for age (Th3/P3/A3). Gynecological transabdominal ultrasound examination revealed an image suitable for age, without signs of pathology, endometrium of $5 \mathrm{~mm}$. Hemoglobin level on first visit was $8 \mathrm{~g} \%$. The patient was diagnosed with severe AUB. Firstly, we tried using dydrogesterone for several months with no effect. Final therapeutic decision was made at the age of 15: we have inserted intrauterine hormonal contraceptive systems (LNG-releasing) under general anesthesia, after obtaining full formal parental consent. Patient's clinical state was re-evaluated after 1, 3 and 6 months. We have observed complete blockage of uterine bleeding with no side effects.

Our second patient was a 15 years old girl with Turner Syndrome (45 X0/46 XX), after 3 years of GH therapy with spontaneous menarche at the age of 11 . In addition, she suffered from congenital heart disease (bipolar aortic valve - mild form, under clinical follow-up) and she had relative contraindications for estrogen use. The patient presented with very abundant menstruation, lasting up to 21 days and irregular menstrual cycles. Her gynecological condition was suitable for age (Th5/P5/A5). Gynecological transabdominal ultrasound examination revealed an image suitable for age, without signs of pathology, endometrium of $8 \mathrm{~mm}$. Hemoglobin level on first visit was $10 \mathrm{~g} \%$. The patient was diagnosed with moderate AUB. First stage therapy consisted of dydrogesterone $10 \mathrm{mg}$ twice a day between $16-25^{\text {th }}$ cycle's days (insufficient effect). Our final therapeutic decision was inserting intrauterine hormonal contraceptive systems (LNGreleasing) at the age of 16.5 under general anesthesia, after obtaining full formal parental consent. Patient's clinical state was re-evaluated after 1, 3 and 6 months. We have observed complete blockage of uterine bleeding with no side effects.

\section{LNG-IUD in the treatment of endometriosis and chronic pelvic pain}

Although LNG-IUD is not dedicated to be used as a first-line treatment of endometriosis and chronic pelvic pain (no registration in SmPC), we have experience in treating young patients with diagnosed endometriosis (off-label treatment). In 6 adolescents we have introduced low-dose LNG-IUD with success. Firstly, the girls were treated with standard methods, unfortunately without any effect. All six patients have not begun their sexual life yet. Formal consent from their parents for implementation of LNG-IUD was required in all 6 cases. Literature lack information about the use of LNG-IUD in adolescents suffering from endometriosis, so we should conduct further research in this topic.

Effects on the menstrual bleeding are expected in most women using the LNG-IUDs. Such changes are the result of a direct effect of levonorgestrel on the endometrium and may not be correlated with ovarian activity. Irregular bleeding and spotting often occur in the first months of use. Then, as a result of strong endometrial inhibition, the duration and reduction of menstrual bleeding are reduced. Minor bleeding often turns into rare bleeding or amenorrhea. In clinical trials, rare bleeding and/or amenorrhea developed gradually. In non-menstrual women, multiple pregnancy tests are not necessary unless there are other signs of pregnancy. If the bleeding gets worse and/or becomes more irregular over time, appropriate diagnostic measures should be taken because irregular bleeding may be a sign of endometrial polyps, hyperplasia or cancer. Heavy bleeding may be also a symptom of expulsion of the intrauterine therapeutic system. In most women, after the IUD is put on, the menstrual bleeding pattern changes. Over time, the percentage of women with amenorrhoea and with rare bleeding increases, while the percentage of women with prolonged, irregular and frequent bleeding decreases [8].

\section{Safety}

Some physicians are concerned about using IUDs in young women because they are higher risk of STIs. However, despite concerns, studies show that insertion of IUD in young women (including teenagers) is not connected with higher risk of STI when compared to older women. The risk of pelvic inflammatory disease (PID) in the first 20 days after insertion is less than $1 \%$, and then decreases to around 1 in 1000 [8]. However, the American Pediatric Society recommends screening for Chlamydia and Neisseria before inserting IUD due to the significant risk of transmission of infections in the adolescent group [9]. We recommend conducting a precise interview (i.e. information about many sexual partners, questions about risk factors of PID, the occurrence of PID in the past) with the patient before introducing the system [8]. In our practice, we have never observed PID in a teenage patient after inserting LNG-IUD.

\section{CONCLUSIONS}

IUDs are considered to be safe and well tolerated method of contraception among adolescents. However, young women often have to face some barriers connected with IUD access (i.e. financial barriers). Gynecologists and pediatricians should be well informed in the topic of IUD use among adolescents and they should provide them reliable knowledge in this field. Teenagers often seek effective, safe and easy method of contraception, which does not require daily reminding. LNG-IUD should be always considered as a method of contraception in young women.

\section{REFERENCES}

1. Badanie Zbigniewa Izdebskiego i Polpharmy Seksualność Polaków 2011. Świat Medycyny i Farmacji z dnia 01.01.2012 r.

2. World Health Organization Contraception in adolescence 2004. https:// apps.who.int/iris/bitstream/handle/10665/42901/9241591447_eng. pdf? sequence $=1$ (28.03.2020). 
3. The reproductive health report: The state of sexual and reproductive health within the European Union. Eur J Contracept Reprod Health Care. 2011; 16 Suppl 1: S1-70, doi: 10.3109/13625187.2011.607690, indexed in Pubmed: 21892901.

4. Rekomendacje Polskiego Towarzystwa Ginekologicznego w sprawie antykoncepcji. (2006) Wydanie specjalne. Ginekol Dypl. 2006: 24-26.

5. Beatty MN, Blumenthal PD. The levonorgestrel-releasing intrauterine system: Safety, efficacy, and patient acceptability. Ther Clin Risk Manag. 2009; 5(3): 561-574, doi: 10.2147/tcrm.s5624, indexed in Pubmed: 19707273.

6. Intrauterine Contraception Translating Research Into Action. Straight to the Point: Talking IUC Simple steps to successfully counselling women about intrauterine contraception (IUC) in under 7 minutes. https:// www.your-life.com/static/media/pdf/educationalmaterial/Booklet_Simple_steps_to_successfully_counselling_women_about_IUC. PDF (28.03.2020).

7. Polis R, Hertweck S. Treatment Options for the Adolescent Patient Experiencing Abnormal Uterine Bleeding. Current Treatment Options in Pediatrics. 2016; 2(3): 184-195, doi: 10.1007/s40746-016-0054-8.

8. Dean G, Schwarz EB. Intrauterine contraceptives. In: Hatcher RA, Contraceptive Technology. 20th rev ed. Ardent Media, New York 2011: 147-19.

9. American Pediatric Society. Contraception for Adolescents. Pediatrics October. 2014; 134(4): e1244-e1256. 